Review

\title{
Aspirin in the Management of Patients with Prostate Cancer Undergoing Radiotherapy: Friend or Foe?
}

\author{
BIANCA MASCAN and LAURE MARIGNOL
}

\author{
Applied Radiation Therapy Trinity, Discipline of Radiation therapy, Trinity College, Dublin, Ireland
}

\begin{abstract}
Aspirin has cyclooxygenase-2 (COX2)-mediated anti-inflammatory and anti-coagulant properties that may confer a positive effect in preventing and limiting the progression of prostate cancer. Prostate cancer has been shown to have poor treatment outcomes due to therapeutic resistance; therefore, COX2 inhibition caused by aspirin could represent an opportunity to augment current therapies. This is particularly of interest to patients undergoing radiation therapy $(R T)$ where inflammation is a common side-effect. This review discusses the evidence for the potential role of aspirin in the management of patients with prostate cancer undergoing $R T$.
\end{abstract}

Prostate cancer $(\mathrm{PCa})$ is the most common malignancy and the second leading cause of cancer-related deaths among males (1). It is a significant health concern that may become increasingly prevalent in the coming years due to the gradual aging of the population (1). In spite of increasing survival rates and improved treatment outcomes $(2,3)$, there is a need to further boost current therapies.

The association between carcinogenesis, inflammation and the coagulatory system is widely recognised $(4,5)$. There are substantial experimental data to suggest that the coagulatory system may modulate many multiple cancer pathways such as those controlling tumour proliferation, angiogenesis and metastasis (6).

The role of inflammation in prostate disease is suggested by the presence of inflammatory cells in benign prostatic hyperplasia and $\mathrm{PCa}(5)$. The prostate has a fully active immunological response which involves a broad spectrum of

Correspondence to: Dr. Laure Marignol, Applied Radiation Therapy Trinity, Discipline of Radiation Therapy, Trinity Centre for Health Sciences, St James's Hospital, Dublin 8, Ireland. Tel: +353 18963255, e-mail: marignl@tcd.ie

Key Words: Aspirin, prostate cancer, radiation, review. intra-epithelial endogenous inflammatory cells such as T-lymphocytes. T-Cells increase with age, which correlates with the incidence of prostate inflammation during the aging process $(5,7)$. T-Cells are known to release factors that stimulate matrix formation and secretion of potent epithelial and stromal mitogens which could promote prostate stromal and epithelial proliferation/hyperplasia (5).

Although a causative link has not been unequivocally established, evidence suggests that recurrent or persistent inflammation may influence susceptibility to, or initiate or promote carcinogenesis (4). Since increased inflammation can increase coagulation, which in turn can enhance inflammation, not using an anticoagulant such as aspirin to control the clotting process would naturally increase the inflammatory process (4).

Non-steroidal anti-inflammatory drugs, including aspirin, have been available for many years and are widely used throughout the world (8). Aspirin as a treatment for cancer is currently of interest $(9,10)$. Randomised trials assessing the effect of aspirin on the cardiovascular system and disease have also collected data on cancer incidence. Rothwell et al. found that aspirin reduced the risk of a cancer diagnosis with a hazard ratio (HR) of 0.88 (11). It has also been reported that aspirin reduced the risk of cancer with metastasis (12). The long-term effect of aspirin on cancer incidence and mortality has been shown to be beneficial in colorectal cancer (12-14), however, not in PCa specifically. As aspirin is commonly used in the PCa population, its potential effect on treatment outcomes is promising (15).

Subsequent research established cyclooxygenase-2 (COX2) as a candidate protein that might explain the effect of aspirin on cancer $(16,17)$. COX2 is an inducible form of the enzyme that catalyses the synthesis of prostanoids, including prostaglandin E2, a major mediator of inflammation and angiogenesis $(18,19)$. COX2 increases the carcinogenic potential of cells through oxidation of procarcinogens to carcinogens, increased cell growth, reduced apoptosis, as well as reduced immune response to abnormal 
or cancer cells. Although the mechanism of COX2 action in carcinogenesis or progression is not well established, COX2 inhibitors have been shown to be chemopreventive in cancer, specifically in colorectal cancer (20).

COX2 overexpression was also reported in prostate tumours (21). Its overexpression correlated with a decrease in apoptosis and an increase in angiogenesis (16). Overexpression of $\mathrm{COX} 2$ is also suggested to be a significant prognostic factor for patients with PCa $(20,22)$.

Thus, aspirin and its anti-inflammatory, anti-coagulant properties may confer a positive effect in preventing and limiting the progression of $\mathrm{PCa}$ (23).

It is believed that COX2 is a survival gene (24) since it renders cells more resistant to apoptotic stresses, e.g. radiation therapy $(\mathrm{RT})(25,26)$. COX2 inhibitors are potent enhancers of tumour response to radiation. RT plays a key role in the management of patients with $\mathrm{PCa}(2,27)$. The anti-inflammatory and anti-coagulant characteristics of aspirin may be particularly important for patients undergoing RT as inflammation is a common side-effect of such treatment (28). RT is delivered in fractions to allow the recovery of normal tissues between treatments. However, surviving cancer cells also proliferate during treatment intervals, leading to repopulation of the tumour and limiting the effectiveness of the treatment. Tumour cell repopulation is a major cause of treatment failure. There is compelling evidence of an active proliferative response, driven by increased COX2 expression, which contributes to the repopulation of tumours and poor patient outcome (18).

At the ages when PCa is usually diagnosed, cardiovascular morbidity is usually already high. Aspirin is one of the most frequently used drugs in cardiovascular disease, and it has been shown to be implicated in prostate carcinogenesis (29, 30). Although PCa can be cured at early stages, the disease in most patients is at a more advanced stage when diagnosed. Endocrinology is used for these patients. Androgen deprivation therapy can induce a series of metabolic changes such as hypertension, atherosclerosis and obesity, in which the perniciousness of cardiovascular disease is serious (31). This further provides encouraging reasons for aspirin use in patients undergoing RT.

Currently, there are no clear, effective treatment options for patients with increasing prostate-specific antigen (PSA) level after definitive RT. The use of chemotherapy in PCa has been uniformly disappointing in both a primary and adjuvant roles (32). It has been reported that aspirin use is associated with significantly lower baseline PSA level in men with PCa who opted for active surveillance for their disease (33), especially those with PSA level $<20 \mathrm{ng} / \mathrm{ml}$. Aspirin may therefore also have an effect on cancer aggressiveness $(8,34)$.

Several investigations have demonstrated that increased COX2 expression is predictive of poor clinical outcomes following primary treatment for PCa $(20,22,35,36)$. Most of these studies evaluated patient outcomes after radical prostatectomy, while the most convincing evidence has resulted from the RTOG 92-02 trial (22), which included patients with locally advanced PCa who were treated with RT plus either short- or long-term androgen deprivation. More specifically, the associations of increased COX2 expression with distant metastasis, biochemical failure, and any failure was demonstrated. Motivated by these findings, this review evaluated the ability of aspirin to augment RT in order to improve biochemical control and PCa-specific mortality (Figure 1).

COX2 has been shown to be involved in $\mathrm{PCa}$, several other types of human cancer, and inflammatory diseases (37). Therefore, the potential use of aspirin, a well-known COX inhibitor, as chemopreventive or therapeutic agent for $\mathrm{PCa}$, is worth being investigated. This review evaluates whether aspirin should be administered to all patients with PCa undergoing RT.

Aspirin is associated with improved biochemical control in patients with PCa undergoing RT. A number of studies have investigated the association between aspirin and its potential to improve biochemical control in PCa (38-41), with some reporting statistically significant associations (38-40), while one study showed conflicting results, finding null effects (41).

Zaorsky et al. found that aspirin use was associated with a two-fold decreased risk of an interval to biochemical failure (IBF) of less than 18 months in RT PCa patients (38). IBF has been shown to be the strongest predictor of distant metastasis, PCa-specific survival and overall survival (42). The authors associated their findings with aspirin's antineoplastic effects. These effects were also found by Choe et al., who retrospectively looked at aspirin use in combination with RT. They found that the 4-year rates of both biochemical failure and distant metastasis were significantly improved with aspirin use. The difference in biochemical control was most prominent for patients in the high-risk group (39). The reported anti-angiogenic properties of aspirin in ovarian cancer may represent an underlying mechanism for the increase in the tumoricidal effect of RT (43). It is possible that blood flow to potentially hypoxic cancer cells is increased, thereby enhancing radiationinduced reactive oxygen species and improving cell kill.

Jacobs et al. found that aspirin was associated with a delayed biochemical relapse benefit in high-risk patients with PCa undergoing RT, which would in turn translate into improved overall survival. However, a major limitation to this study was the small number of patients $(n=27)(40)$.

In contradiction to the above findings, null results were found by Dhillon et al. in regards to metastatic or fatal PCa (41), suggesting that aspirin does not have an impact on biochemical control for patients undergoing RT. 
The findings with regards to the effect of aspirin on disease severity and biochemical control require further confirmation in larger studies. Considering the high incidence of $\mathrm{PCa}$ and the widespread of aspirin use in the general population (44), confirmation of these findings could have a major impact on public health.

Aspirin improves $P$ Ca-specific mortality in patients with $P C a$ undergoing $R T$. A number of studies have investigated the association between aspirin and improved PCa-specific mortality (45-51) but have shown conflicting results, with the majority finding null effects (48-51), while some reported statistically significant associations (45-47).

A systematic review and meta-analysis by Liu et al. provides additional support for the hypothesis that aspirin should be administered to all patients with PCa undergoing RT (45).

In the Cancer of the Prostate Strategic Urologic Research Endeavor database, patients with localised PCa treated with RT, after a follow up of 70 months, aspirin use was independently associated with a lower risk of PCa-specific mortality with a $p$-value of 0.02 . Ten-year mortality was also found to be significantly different at $3 \%$ for those taking aspirin compared to $8 \%$ for those who did not (46).

Although studies have reported mixed results regarding aspirin use and PCa mortality rates, the study by Jacobs et al. (47) included a larger cohort (7118 patients) than previous articles, as well as data regarding aspirin dose, which, according to the authors, is lacking in other studies.

As to be expected, most aspirin users had cardiovascular disease or diabetes in this study, as the primary indication for aspirin is the prevention of cardiovascular disease. However, analysis using Cox proportional hazard models adjusting for age, tumour extent, lymph node involvement etc., aspirin use and decreased mortality rates were not found to be statistically significantly associated.

In a subset analysis of high-risk patients, aspirin was found to be associated with a lower PCa-specific mortality rate, with a HR of 0.60 (47). The results of this study indicate that daily aspirin use was associated with a $40 \%$ lower mortality rate in high-risk patients. This is closely related to the importance of biochemical control, adding to the controversy on this topic.

Contradictory to the findings of the above studies, Cardwell et al. found no association between aspirin use and PCa-specific mortality after potential confounders such as Gleason score were accounted for (48). This study, therefore, did not provide any evidence of a reduction in mortality risk.

Similar to these latter studies, Caon et al. (49) found that aspirin did not have an impact on survival, therefore nor on mortality.

Flahavan et al. reported a small, non-significant reduced risk of prostate cancer specific mortality on multivariate analysis (50). This was also supported by Assayag et al.,

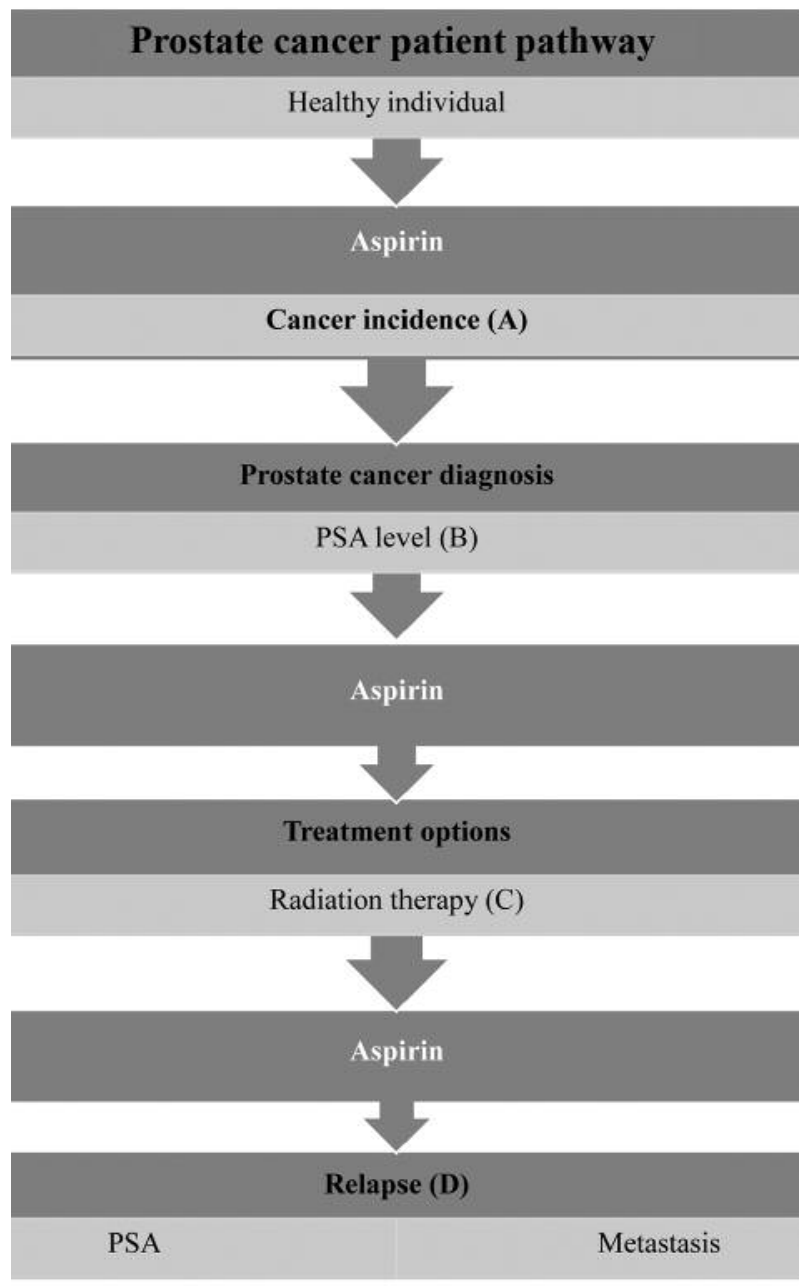

Figure 1. Schematic representation of the potential impact of aspirin throughout the prostate cancer patient management pathway. A: Cancer incidence. Aspirin, a known cyclooxygenase-2 (COX2) inhibitor has been found to reduce the risk of cancer incidence. A chemopreventive role has also been reported in colorectal cancer. COX2 increases the carcinogenic potential of cells through the oxidation of pro-carcinogens to carcinogens, increased cell growth, reduced apoptosis, as well as reduced immune response to abnormal or cancer cells. B: Prostate Specific Antigen (PSA) level. Aspirin was found to be associated with significantly lower baseline PSA levels in men with PCa who opted for active surveillance. C: Radiation therapy. COX2 was found to be involved in tumour resistance to radiation. Aspirin may be a potent enhancer of tumour response to radiation. D: Relapse. Aspirin was reported to reduce the risk of metastasis. It may also possibly have an effect on cancer aggressiveness. COX2 inhibition caused by aspirin has been reported to reduce distant metastasis risk and biochemical relapse.

who found that aspirin use was not associated with a decreased risk of PCa outcomes such as death (51). Interestingly, this study found that aspirin use was associated with an increased risk of PCa mortality ( $\mathrm{HR}=1.37,95 \%$ confidence interval $=1.26-1.50)$. The authors highlighted that 
the increase in mortality risk may be related to $\mathrm{PCa}$ progression. This is inconsistent once again with what was found in the previous argument on biochemical control and disease progression. Taken together, these results argue against a protective association between the use of aspirin and the risk of PCa mortality.

It is important to note that, for example, none of the patients included by Choe et al. had node-positive or metastatic disease, $72 \%$ had $\mathrm{T} 1$ disease and virtually all patients had intracapsular disease (46). Thus, it seems unlikely that aspirin could reduce the risk of recurrence and progression and not the risk of PCa mortality.

Caution needs to be exercised to ensure the associated benefits outweigh the potential side-effects, for example, gastrointestinal bleeding. Although data are limited, it is logical to assume that aspirin can significantly influence the risk of bleeding (52). Bleeding is a common complication of anticoagulant therapy (53), and for patients undergoing RT, bleeding toxicity is expected to be even greater, especially with dose-escalating techniques such as Intensity Moderated Radiation Therapy (IMRT) (54). Grade 3 rectal bleeding was reported in a prospective study of 57 men undergoing RT for $\mathrm{PCa}$ and taking high-dose aspirin (55). Aspirin, even at low doses, can double the incidence of gastric bleeding (56).

\section{Conclusion}

Despite the overwhelmingly large number of patients examined across the 11 studies reviewed here, the evidence for the effects of aspirin on biochemical control and $\mathrm{PCa}$ mortality remain difficult to interpret. This is firstly because of the heterogeneity in the patient population studies, associated with differences in the definition of exposure, statistical analysis, information collection methods (for example medical records), age, lifestyle, race, sample size, duration of study follow-up, etc. Second, this is because of the retrospective, observational nature of the included studies.

Prospective, randomised studies are needed to confirm these findings and determine the optimal dosage and duration of aspirin administration, as well as the risks and benefits associated with its use. Such randomized control trials are difficult to conduct, firstly because PCa mainly occurs in older men, and secondly because too many people in the general population take aspirin for various important medical reasons.

The proposed Add-Aspirin trial (57) has the potential to close this debate. The authors are aiming to recruit 10,000 patients who have had radical treatment for cancer, including PCa. Participants will receive standard adjuvant therapy according to local protocols, and then be randomised to receive aspirin or placebo daily for 5 years with a primary outcome measure based on survival. Outcomes of this work may clarify the clinical potential of aspirin as an adjuvant therapy for patients with PCa undergoing RT.

\section{Conflicts of Interest}

Both Authors have no conflict of interest to declare.

\section{Acknowledgements}

There was no funding support for this work.

\section{References}

1 De Nunzio C, Kramer G, Marberger M, Montironi R, Nelson W, Schröder F, Sciarra A and Tubaro A: The controversial relationship between benign prostatic hyperplasia and prostate cancer: The role of inflammation. European Urology 60(1): 106117, 2011.

2 Fahmy O, Khairul-Asri MG, Hadi S, Gakis G and Stenzl A: The role of radical prostatectomy and radiotherapy in treatment of locally advanced prostate cancer: A systematic review and metaanalysis. Urol Int 99(3): 249-256, 2017.

3 Ryan ST and Sammon JD: Prostate cancer: Radiotherapy might improve survival, even in the oldest men. Nat Rev Urol 13(8): 444-445, 2016.

4 Esmon CT: The interactions between inflammation and coagulation. Br J Haematol 131(4): 417-430, 2005.

5 Hamid AR, Umbas R and Mochtar CA: Recent role of inflammation in prostate diseases: Chemoprevention development opportunity. Acta Med Indones 43(1): 59-65, 2011.

6 Elwood PC, Gallagher AM, Duthie GG, Mur LAJ and Morgan G: Aspirin, salicylates, and cancer. The Lancet 373(9671): 13011309, 2009.

7 Armstrong AJ and Carducci MA: Novel therapeutic approaches to advanced prostate cancer. Clin Adv Hematol Oncol 3(4): 271282, 2005.

8 Stock DC, Groome PA, Siemens DR, Rohland SL and Song Z: Effects of non-selective non-steroidal anti-inflammatory drugs on the aggressiveness of prostate cancer. Prostate 68(15): 16551665,2008

9 Phillips I, Langley R, Gilbert D and Ring A: Aspirin as a treatment for cancer. Clin Oncol (R Coll Radiol) 25(6): 333-335, 2013.

10 Langley RE, Burdett S, Tierney JF, Cafferty F, Parmar MK and Venning G: Aspirin and cancer: Has aspirin been overlooked as an adjuvant therapy? Br J Cancer 105(8): 1107-1113, 2011.

11 Rothwell PM, Price JF, Fowkes FG, Zanchetti A, Roncaglioni MC, Tognoni G, Lee R, Belch JF, Wilson M, Mehta Z and Meade TW: Short-term effects of daily aspirin on cancer incidence, mortality, and non-vascular death: Analysis of the time course of risks and benefits in 51 randomised controlled trials. Lancet 379(9826): 1602-1612, 2012.

12 Rothwell PM, Wilson M, Price JF, Belch JF, Meade TW and Mehta Z: Effect of daily aspirin on risk of cancer metastasis: A study of incident cancers during randomised controlled trials. Lancet 379(9826): 1591-1601, 2012.

13 Rothwell PM, Wilson M, Elwin C-E, Norrving B, Algra A, Warlow CP and Meade TW: Long-term effect of aspirin on colorectal cancer incidence and mortality: 20-year follow-up of five randomised trials. The Lancet 376(9754): 1741-1750, 2010.

14 Bruno A, Dovizio M, Tacconelli $S$ and Patrignani P: Mechanisms of the antitumoural effects of aspirin in the gastrointestinal tract. Best Practice \& Research Clinical Gastroenterology 26(4): e1-e13, 2012. 
15 Choe KS, Cowan JE, Carroll PR, D'Amico AV and Liauw SL: Aspirin use and the risk of prostate cancer death in men treated with prostatectomy or radiotherapy: Results from the capsure database. Int J Radiat Oncol Biol Phys 78(3 Suppl): S126-S127, 2010.

16 Kim BH, Kim CI, Chang HS, Choe MS, Jung HR, Kim DY and Park $\mathrm{CH}$ : Cyclooxygenase-2 overexpression in chronic inflammation associated with benign prostatic hyperplasia: Is it related to apoptosis and angiogenesis of prostate cancer? Korean J Urol 52(4): 253-259, 2011.

$17 \mathrm{Xu}$ XC: Cox-2 inhibitors in cancer treatment and prevention, a recent development. Anti-Cancer Drugs 13(2): 127-137, 2002.

18 Pang LY, Hurst EA and Argyle DJ: Cyclooxygenase-2: A role in cancer stem cell survival and repopulation of cancer cells during therapy. Stem Cells Int 2016: 2048731, 2016.

19 Richardsen E, Uglehus RD, Due J, Busch C and Busund LT: Cox-2 is overexpressed in primary prostate cancer with metastatic potential and may predict survival. A comparison study between cox-2, tgf-beta, il-10 and ki67. Cancer Epidemiol 34(3): 316-322, 2010.

20 Cohen BL, Gomez P, Omori Y, Duncan RC, Civantos F, Soloway MS, Lokeshwar VB and Lokeshwar BL: Cyclooxygenase-2 (cox2) expression is an independent predictor of prostate cancer recurrence. Int J Cancer 119(5): 1082-1087, 2006.

21 Anai S, Tanaka M, Shiverick KT, Kim W, Takada S, Boehlein S, Goodison S, Mizokami A and Rosser CJ: Increased expression of cyclooxygenase- 2 correlates with resistance to radiation in human prostate adenocarcinoma cells. J Urol 177(5): 1913-1917, 2007.

22 Khor LY, Bae K, Pollack A, Hammond ME, Grignon DJ, Venkatesan VM, Rosenthal SA, Ritter MA, Sandler HM, Hanks GE, Shipley WU and Dicker AP: Cox-2 expression predicts prostate-cancer outcome: Analysis of data from the rtog 92-02 trial. Lancet Oncol 8(10): 912-920, 2007.

23 Pruthi RS and Wallen EM: Cyclooxygenase-2: A therapeutic target for prostate cancer. Clin Genitourin Cancer 4(3): 203-211, 2005 .

24 Gaffney DK, Holden J, Zempolich K, Murphy KJ, Dicker AP and Dodson M: Elevated cox-2 expression in cervical carcinoma: Reduced cause-specific survival and pelvic control. Am J Clin Oncol 24(5): 443-446, 2001.

25 Eisen $\mathrm{V}$ and Walker DI: Effect of ionizing radiation on prostaglandin 15-oh-dehydrogenase (pgdh) [proceedings]. Br J Pharmacol 62(3): 461p, 1978.

26 Nakata E, Mason KA, Hunter N, Husain A, Raju U, Liao Z, Ang KK and Milas L: Potentiation of tumor response to radiation or chemoradiation by selective cyclooxygenase- 2 enzyme inhibitors. Int J Radiat Oncol Biol Phys 58(2): 369-375, 2004.

27 Benjamin LC, Tree AC and Dearnaley DP: The role of hypofractionated radiotherapy in prostate cancer. Curr Oncol Rep 19(4): 30, 2017.

28 Mak RH, Hunt D, Efstathiou JA, Heney NM, Jones CU, Lukka HR, Bahary JP, Patel M, Balogh A, Nabid A, Leibenhaut MH, Hamstra DA, Roof KS, Jeffrey Lee R, Gore EM, Sandler HM and Shipley WU: Acute and late urinary toxicity following radiation in men with an intact prostate gland or after a radical prostatectomy: A secondary analysis of rtog 94-08 and 96-01. Urol Oncol 34(10): 430.e431-437, 2016.

29 Mahmud S, Franco E and Aprikian A: Prostate cancer and use of nonsteroidal anti-inflammatory drugs: Systematic review and meta-analysis. Br J Cancer 90(1): 93-99, 2004.
30 Olivan M, Rigau M, Colas E, Garcia M, Montes M, Sequeiros T, Regis L, Celma A, Planas J, Placer J, Reventos J, de Torres I, Doll A and Morote J: Simultaneous treatment with statins and aspirin reduces the risk of prostate cancer detection and tumorigenic properties in prostate cancer cell lines. Biomed Res Int 2015: 762178, 2015.

31 Li XX, Zhang YG, Wang D, Chen YF and Shan YH: Preventive effects of aspirin on cardiovascular complications in prostate cancer cases after endocrinotherapy. Asian Pac J Cancer Prev 16(12): 4909-4913, 2015.

32 Johnstone RW, Frew AJ and Smyth MJ: The trail apoptotic pathway in cancer onset, progression and therapy. Nat Rev Cancer 8(10): 782-798, 2008.

33 Algotar AM, Thompson PA, Ranger-Moore J, Stratton MS, Hsu $\mathrm{CH}$, Ahmann FR, Nagle RB and Stratton SP: Effect of aspirin, other nsaids, and statins on psa and psa velocity. Prostate 70(8): 883-888, 2010.

34 Alizadeh M, Sylvestre M-P, Zilli T, Van Nguyen T, Guay J-P, Bahary J-P and Taussky D: Effect of statins and anticoagulants on prostate cancer aggressiveness. Int J Radiat Oncol Biol Phys 83(4): 1149-1153, 2012.

35 Rubio J, Ramos D, Lopez-Guerrero JA, Iborra I, Collado A, Solsona E, Almenar S and Llombart-Bosch A: Immunohistochemical expression of ki-67 antigen, cox-2 and bax/bcl-2 in prostate cancer; prognostic value in biopsies and radical prostatectomy specimens. Eur Urol 48(5): 745-751, 2005.

36 Di Lorenzo G, De Placido S, Autorino R, De Laurentiis M, Mignogna C, D'Armiento M, Tortora G, De Rosa G, De Sio M, Bianco AR and D'Armiento FP: Expression of biomarkers modulating prostate cancer progression: Implications in the treatment of the disease. Prostate Cancer Prostatic Dis 8(1): 54-59, 2005.

37 Cai Y, Lee YF, Li G, Liu S, Bao BY, Huang J, Hsu CL and Chang C: A new prostate cancer therapeutic approach: Combination of androgen ablation with cox-2 inhibitor. Int J Cancer 123(1): 195-201, 2008.

38 Zaorsky NG, Buyyounouski MK, Li T and Horwitz EM: Aspirin and statin nonuse associated with early biochemical failure after prostate radiation therapy. Int J Radiat Oncol Biol Phys 84(1): e13-e17, 2012.

39 Choe KS, Correa D, Jani AB and Liauw SL: The use of anticoagulants improves biochemical control of localized prostate cancer treated with radiotherapy. Cancer 116(7): 1820-1826, 2010.

40 Jacobs CD, Chun SG, Yan J, Xie XJ, Pistenmaa DA, Hannan R, Lotan Y, Roehrborn CG, Choe KS and Kim DWN: Aspirin improves outcome in high risk prostate cancer patients treated with radiation therapy. Cancer Biol Ther 15(6): 699-706, 2014.

41 Dhillon PK, Kenfield SA, Stampfer MJ, Giovannucci EL and Chan JM: Aspirin use after a prostate cancer diagnosis and cancer survival in a prospective cohort. Cancer Prev Res (Phila) 5(10): 1223-1228, 2012

42 Buyyounouski MK, Pickles T, Kestin LL, Allison R and Williams SG: Validating the interval to biochemical failure for the identification of potentially lethal prostate cancer. J Clin Oncol 30(15): 1857-1863, 2012.

43 Huang Y, Lichtenberger LM, Taylor M, Bottsford-Miller JN, Haemmerle M, Wagner MJ, Lyons Y, Pradeep S, Hu W, Previs RA, Hansen JM, Fang D, Dorniak PL, Filant J, Dial EJ, Shen F, Hatakeyama $\mathrm{H}$ and Sood AK: Antitumor and antiangiogenic effects of aspirin-pc in ovarian cancer. Mol Cancer Ther 15(12): 2894-2904, 2016. 
44 Cuzick J, Thorat MA, Bosetti C, Brown PH, Burn J, Cook NR, Ford LG, Jacobs EJ, Jankowski JA, La Vecchia C, Law M, Meyskens F, Rothwell PM, Senn HJ and Umar A: Estimates of benefits and harms of prophylactic use of aspirin in the general population. Ann Oncol 26(1): 47-57, 2015.

45 Liu Y, Chen JQ, Xie L, Wang J, Li T, He Y, Gao Y, Qin X and Li S: Effect of aspirin and other non-steroidal anti-inflammatory drugs on prostate cancer incidence and mortality: A systematic review and meta-analysis. BMC Med 12: 55, 2014.

46 Choe KS, Cowan JE, Chan JM, Carroll PR, D'Amico AV and Liauw SL: Aspirin use and the risk of prostate cancer mortality in men treated with prostatectomy or radiotherapy. J Clin Oncol 30(28): 3540-3544, 2012.

47 Jacobs EJ, Newton CC, Stevens VL, Campbell PT, Freedland SJ and Gapstur SM: Daily aspirin use and prostate cancer-specific mortality in a large cohort of men with nonmetastatic prostate cancer. J Clin Oncol 32(33): 3716-3722, 2014.

48 Cardwell CR, Flahavan EM, Hughes CM, Coleman HG, O'Sullivan JM, Powe DG and Murray LJ: Low-dose aspirin and survival in men with prostate cancer: A study using the uk clinical practice research datalink. Cancer Causes Control 25(1): 33-43, 2014.

49 Caon J, Paquette M, Hamm J and Pickles T: Does statin or asa affect survival when prostate cancer is treated with external beam radiation therapy? Prostate Cancer 2014: 184297, 2014.

50 Flahavan EM, Bennett K, Sharp L and Barron TI: A cohort study investigating aspirin use and survival in men with prostate cancer. Ann Oncol 25(1): 154-159, 2014.

51 Assayag J, Pollak MN and Azoulay L: The use of aspirin and the risk of mortality in patients with prostate cancer. J Urol 193(4): 1220-1225, 2015.

52 Choe KS, Jani AB and Liauw SL: External beam radiotherapy for prostate cancer patients on anticoagulation therapy: How significant is the bleeding toxicity? Int J Radiat Oncol Biol Phys 76(3): 755-760, 2010.
53 Derry S and Loke YK: Risk of gastrointestinal haemorrhage with long term use of aspirin: Meta-analysis. Bmj 321(7270): 11831187, 2000.

54 Budaus L, Bolla M, Bossi A, Cozzarini C, Crook J, Widmark A and Wiegel T: Functional outcomes and complications following radiation therapy for prostate cancer: A critical analysis of the literature. Eur Urol 61(1): 112-127, 2012.

55 D’Amico AV, Manola J, McMahon E, Loffredo M, Lopes L, Ching J, Albert M, Hurwitz M, Suh WW, Vivenzio TA and Beard C: A prospective evaluation of rectal bleeding after doseescalated three-dimensional conformal radiation therapy using an intrarectal balloon for prostate gland localization and immobilization. Urology 67(4): 780-784, 2006.

56 Hernandez-Diaz S and Rodriguez LA: Incidence of serious upper gastrointestinal bleeding/perforation in the general population: Review of epidemiologic studies. J Clin Epidemiol 55(2): 157-163, 2002.

57 Coyle C, Cafferty FH, Rowley S, MacKenzie M, Berkman L, Gupta S, Pramesh CS, Gilbert D, Kynaston H, Cameron D, Wilson RH, Ring A, Langley RE and Add-Aspirin i: Add-aspirin: A phase iii, double-blind, placebo controlled, randomised trial assessing the effects of aspirin on disease recurrence and survival after primary therapy in common non-metastatic solid tumours. Contemp Clin Trials 51: 56-64, 2016. 